\title{
Capacitação de Profissionais sob a Perspectiva da Redução de Danos: drogas, vamos pensar!
}

\begin{aligned} & \hline \multirow{3}{*}{ Samantha Torres } Centro de Atenção Psicossocial Álcool e Dro- \\ & gas, Viamão, RS, Brasil. Colegiado gestor do \\ & CRR - Rede Multicêntrica, Universidade Fede- \\ & ral do Rio Grande do Sul (UFRGS), Instituto de \\ & Psicologia, Porto Alegre, RS, Brasil. \\ & E-mail: torres.samantha@gmail.com \\ & Doutorando do Programa de Pós-Graduação \\ & em Psicologia Social e Institucional (PPGPSI), \\ & Daniel Dall'Igna Ecker Instituto de Psicologia (UFRGS), Porto Alegre, \\ & RS, Brasil. \\ & E-mail: daniel.ecker@hotmail.com \\ &\end{aligned}

Recebido em: 10 out. 2016. Revisado: 24 nov. 2016. Aceito: 24 jan. 2017. DOI: http://dx.doi.org/10.21674/2448-0479.31.39-62

\section{Resumo}

Este artigo tem como objetivo trazer para reflexão o tema das drogas. Como material de dispositivo para análise, apresentamos o relato de experiência de uma capacitação sobre o assunto, oferecida a profissionais de serviços públicos. A partir da capacitação, visamos compreender o que cada um dos profissionais entendia por droga e se já haviam feito o uso de substâncias. Por meio dos debates realizados, elencamos 5 grandes temas que permearam a discussão e as respostas dos profissionais, foram eles: 1) Drogas e Saúdes; 2) Drogas e Efeitos; 3) Drogas e Materialidades; 4) Drogas 
e Seres Humanos; 5) Drogas e Conceitos. Através da reflexão sobre esses cinco temas, questionamos a forma como a temática das drogas ainda é envolta por muitas ações de censura e por uma multiplicidade de interpretações. Assim, assumindo a falência dessa estratégia nas políticas de cuidado que têm se mostrado eficazes, afirmamos a importância do pensar sobre as drogas como meio para o tratamento dos usuários que fazem uso problemático, com base na reflexão sobre o uso, responsabilização e auto-gestão de todos os envolvidos.

Palavras-chave: Uso de drogas. Capacitação Profissional. Relato de Experiência.

\section{Abstract \\ Training of professionals throught the Dam- age reduction perspective: Drugs, let's think}

This article presents reflections about the issue of drug use. As a material to support the discussion, we bring a experience report from a training on the theme offered to public service professionals. During the training, we propose to comprehend what each of the professionals understand by the word drug and what kind of drug use they have ever did. Thought the debate, we pointed out 5 major themes that permeated the discussion and the answers of professionals, they was: 1) Drugs and Health; 2) Drugs and Effects; 3) Drugs and Materialities; 4) Drugs and Human Beings; 5) Drugs and Concepts. Through reflection on these five themes, we question how the drugs debate is still permeated by censorships and a multiplicity of meanings. Thus, assuming the failure of this strategy in care policies that 
have been effective, we affirm the importance in think about drugs as a strategy on the treatment of users who have problematic use, based on reflection on the use, accountability and self-management of all involved.

Keywords: Drug use. Training professionals. Experience report.

\section{Introdução}

Recorrentemente escutamos que um dos elementos que diferencia o ser humano dos animais é sua capacidade de pensar e refletir sobre si no mundo. $O$ argumento de que os humanos são seres racionais, por vezes, é usado como forma de colocar as pessoas em um patamar de superioridade, quase como uma marca de poder que distinguiria os humanos de outros animais. Sob essa perspectiva, o pensar, o debater e o refletir sobre os diversos aspectos da vida seriam quase como elementos inerentes ao que caracterizariam o ser humano. Nesse raciocínio, pensamos: qual o significado e o objetivo de serem realizadas campanhas para não se pensar sobre determinados assuntos se o humano, como alguns argumentam, é um ser essencialmente racional?

Uma campanha muito difundida nos últimos anos, elaborada por uma grande mídia, tinha como slogan a expressão "Crack, nem Pensar!" (GRUPO RBS, 2009). Entendemos que neste slogan o que se trata não é necessariamente o 'nem pensar' no sentido do pensamento, mas o 'nem pensar' no sentido de não experimentar, de manter afastado, do sujeito, o objeto considerado droga - o crack. Porém, esse 'nem pensar', esse estimulo à repulsa, traz um interdito à reflexão sobre o assunto pois, além de tratar como óbvia a ideia de que não se pode experimentar ou usar a substância (como se a 
mesma fosse por si só um grande malefício), também estigmatiza no crack o discurso da interdição. Com essa campanha, entendemos que houve a construção de um tabu em relação à esta substância, no sentido de as pessoas falarem do crack apenas como algo que precisaria ser evitado e repulsado. Como a grande parte dos tabus, oculta-se algo que está presente no cotidiano humano, o que impede que esse cotidiano seja colocado em análise.

Compreendemos que, se existe um fenômeno acontecendo na sociedade, além de tentarmos anular sua existência, acobertando-o com discursos morais sob o argumento do perigo ou da interdição, é preciso refletir sobre ele: tentar compreender o porquê do surgimento do fenômeno, o que ele significa e ao que ele vem dar conta em uma determinada conjuntura político-social. Exemplificamos a estratégia de censura com o discurso sobre o uso do crack mas, dentre os desafios presentes no campo da Redução de Danos, poderiam ser citadas diversas outras situações que envolvem padrões morais, convenções sociais, religiosas ou culturais, em torno do uso de substâncias químicas.

Frente a essas diversas fontes de interdição no campo do uso de drogas objetivamos, neste artigo, trazer para reflexão o tema das drogas sob a perspectiva da Redução de Danos: Drogas, vamos pensar!. Como material de dispositivo para análise, apresentamos o relato de experiência de uma capacitação sobre a temática das drogas, oferecida a profissionais de serviços públicos. Trazer para reflexão a problemática discursiva que envolve o tema das drogas não significa, com isso, que se esteja defendendo o uso indiscriminado de drogas e que todos os usos 'são bons', 'legais' e devam ser socialmente aceitos. A reflexão busca, na verdade, entender a complexidade que o tema do uso de substâncias envolve, sem cair em dicotomias simplistas do 'certo' e 'errado' que negam a complexidade do tema e, por vezes, produzem profissionais nos serviços que atuam de forma moralizante e superficial. 
Infelizmente, grande parte das campanhas sobre o uso de drogas ainda são formuladas pautadas por moralismos discriminatórios. É a esse tipo de campanha, estudos e demandas, que não podemos responder mecanicamente como se estas fossem óbvias, claras e consideradas 'verdades absolutas'. Quando falamos de seres humanos, e o discurso sobre sua gestão, sob argumentos demasiadamente claros, óbvios e lógicos, é preciso um pouco de desconfiança. Antes de mais nada, é necessário entendermos que o ser humano é um ser complexo, por vezes irracional, não lógico, que vive em determinada cultura, e num dado tempo histórico. Existem valores na contemporaneidade, que nem sempre foram assim e nem sempre serão. Reconhecendo que as realidades mudam no decorrer do tempo, torna-se inviável e falsa a tentativa de estabelecer verdades absolutas sobre o ser humano. Que outros modos de analisar e de se relacionar com o fenômeno do uso de substâncias existiram/existem/existirão? Há apenas um caminho no trabalho com usuários de drogas?

Pensamos que toda a trabalhadora e todo o trabalhador, seja de serviço público ou privado, deveria desconfiar um pouco mais dos objetivos e resultados que seu trabalho lhe impõe. Afinal, 'para o quê' e 'para quem' estão sendo demandadas respostas sobre o comportamento humano? Através de nossa prática, percebemos que muitos profissionais partem de certas verdades impostas pelas políticas públicas, ou por suas próprias perspectivas de vida, para executarem suas tarefas sem ao menos desconfiar de onde surgem tais verdades e ao que elas vêm dar conta. O risco de se atuar em verdades dadas a priori, sem ao menos colocá-las em análise, é acabar servindo como ferramenta não pensante da máquina de tabus que, infelizmente, ainda sustenta nosso ser social. Construída em cima de profundas desigualdades e injustiças, essa maquinaria reflete um sistema social que é permeado por práticas humanas perversas, que alavanca injustiças, travestindo-se de 'boas ideias', 
práticas de 'prevenção' ou ações 'corretas e óbvias'.

\section{Capacitando profissionais sobre o uso de drogas}

Como dispositivo para embasar esta reflexão, trazemos discussões que se fizeram presentes em um levantamento de conceitos sobre drogas, usos e experiências, que fora obtido a partir de uma capacitação sobre o tema, oferecido a profissionais de serviços públicos. Como forma de introduzir as aulas do dia, a proposta deste levantamento foi compreender o que cada um dos profissionais entendia por 'droga' e que tipo de drogas 'cada um ali já havia feito uso, ou mantinha-se fazendo'. No total, foram 25 profissionais que responderam esse levantamento, de forma anônima, em uma folha em branco. Os resultados foram diversos e, por isso, organizados a partir de semelhanças temáticas. Através dos temas emergentes, realizamos rodas de debates com reflexões sobre o tema, com duração de 3h, estimulando o pensar sobre as drogas! Após o fim dessa atividade, efetuamos o agrupamento dos materiais em 5 grandes temas, elencados por similitudes discursivas, presentes no levantamento e nas discussões das rodas, foram eles: 1) Drogas e Saúdes; 2) Drogas e Efeitos; 3) Drogas e Materialidades; 4) Drogas e Seres Humanos; 5) Drogas e Conceitos. A organização e análise dos temas seguiram a própria metodologia da atividade, mantendo o arranjo das falas em torno das perguntas disparadoras: o que você entende por droga? Que drogas você usa ou já fez uso?

Esta atividade integrou as ações da Rede Multicêntrica e, por nossa experiência no tema e na execução desta atividade em outras turmas, percebemos que quando as pessoas adentram a capacitação, que tem como tema as drogas, elas já ingressam sob certas ideias sobre o assunto, pois a palavra drogas incita diferentes pensamentos, valorações e uma série de estereótipos sociais. Não negamos que, na conjuntura social atual, potencializada pelas veicula- 
ções da mídia, a ideia sobre drogas ainda é difundida como algo negativo, que precisa ser censurada, colocada no patamar dos problemas sociais graves. Então, quando propomos falar sobre drogas com os serviços, compreendemos que partimos de narrativas construídas historicamente que, vê na relação do ser humano com as substâncias, uma série de estereótipos e fabricações discursivas (GOMIDE, 2010).

Porém, o uso de substâncias sempre foi algo problemático? Em todas as sociedades o uso de substâncias é considerado algo problemático? Por que algumas substâncias são criminalizadas e outras não? Que interesses existem em criminalizar determinadas substâncias e outras não? O uso do álcool, por exemplo, como discute Guareschi et al. (2015) já foi considerado uma das causas da criminalidade, do caos social e, inclusive, da loucura. Segundo as autoras, era recorrente na década de 1930 discursos que situavam o álcool como futura epidemia social, semelhante como se entendia a tuberculose e a varíola naquela época. O álcool já fora colocado como ameaça ao processo civilizatório, sendo situado como "[...] o principal responsável pelo pauperismo, pelo abandono do lar, pela imoralidade, pela vadiagem, pelo crime e depravação social" (GUARESCHI et al. apud PENNA, 1929, p. 2).

Esse fragmento evidencia como se torna interessante tornar visível sobre como os discursos sobre o uso de drogas se transformam ao longo dos anos e, provavelmente, nem fosse possível pensar naquela época que, anos depois, o álcool seria uma substância tão consumida mundialmente, alvo de grandes publicidades e um dos produtos centrais na geração econômica de diversos países. Assim, o exercício que propomos aqui de questionarmos termos, pensando sobre a palavra 'drogas', permite a desestabilização das noções de sujeitos, modos de ser e estar no mundo que vem diretamente colados à discursos constituídos locais e historicamente. 
Esse exercício, parte da produção de um saber científico aproximado das discussões propostas pelo filósofo Michel Foucault. Os estudos de Foucault têm contribuído para uma ampla desnaturalização dos campos de pesquisa da Psicologia Social ao propor que os saberes da área sejam questionados e situados como possíveis de vincularem-se ou serem vinculados à produção de realidades e modos de subjetivação específicos (HÜNING; GUARESCHI, 2009). Ao propormos trazer para a análise os discursos em torno do uso de drogas, afirmamos a importância da organização dos saberes, poderes e domínios de objetos em torno desse tema ao longo do processo histórico no país.

O próprio termo drogas, por exemplo, fora cunhado tendo como origem a palavra drogg, proveniente do holandês antigo, cujo significado é folha seca. Esta denominação é devido ao fato de que, antigamente, quase todos os medicamentos utilizavam-se de vegetais em sua composição (GÓIS; AMARAL, 2016). Inicialmente, então, a palavra droga não era entendida como hoje comumente se compreende. De certa forma, até hoje o termo drogas não se refere ao uso dependente de uma substância. Os medicamentos vendidos em farmácias também são drogas e, tanto é assim, que muitas farmácias são chamadas de drogarias.

\section{Discussão sobre drogas com os profissionais}

A variabilidade de possibilidades em entender o termo 'droga' evidencia-se na lista de substâncias que foi formulada junto aos profissionais envolvidos nas atividades de capacitação da Rede Multicêntrica (Tabela 1). Não havia limite para a citação de itens, então alguns colocaram mais de uma substância. O número ao lado 
esquerdo da substância se refere a quantidade de profissionais que a citaram. A pergunta era: que drogas você usa ou já fez uso?

Tabela 1 - Potenciais "drogas" conforme mencionado pelos respondentes (entre parênteses o número de respostas - n).

\begin{tabular}{|l|l|}
\hline Álcool $(n=23)$ & Compras $(n=01)$ \\
\hline Cigarro $(n=16)$ & Sexo $(n=01)$ \\
\hline Medicamentos $(n=14)$ & Cocaína $(n=01)$ \\
\hline Maconha $(n=12)$ & Sal $(n=01)$ \\
\hline Café $(n=11)$ & Analgésico $(n=01)$ \\
\hline Chocolate $(n=05)$ & Relaxante muscular $(n=01)$ \\
\hline Antidepressivos $(n=04)$ & Anti-inflamatório $(n=01)$ \\
\hline Chimarrão $(n=03)$ & Paracetamol $(n=01)$ \\
\hline Ansiolíticos $(n=03)$ & Antibiótico $(n=01)$ \\
\hline Açúcar $(n=03)$ & Trabalho $(n=01)$ \\
\hline Coca-cola $(n=02)$ & Moderador de apetite $(n=01)$ \\
\hline LSD $(n=02)$ & Religião $(f a n a t i s m o)(n=01)$ \\
\hline Facebook $(n=01)$ & Consumismo $(n=01)$ \\
\hline Solvente $(n=01)$ & Excessos $(n=01)$ \\
\hline Refrigerante $(n=01)$ & Aprisionamentos $(n=01)$ \\
\hline Revista Veja $(n=01)$ & Celular $(n=01)$ \\
\hline Gordura $(n=01)$ & Comida $(n=01)$ \\
\hline
\end{tabular}

É interessante notar que dos 25 profissionais do serviço público 23 deles citaram que fazem ou já fizeram uso do álcool. O álcool, apesar de ser uma droga lícita, hoje já possui estudos que comprovam ser 114 vezes mais letal que a maconha. Porém, o álcool está ai nas ruas, nas festas, nos encontros, sendo vendido e usado publicamente, sem restrições (LACHENMEIER; REHM, 2015). Contudo, nesse mesmo estudo, os autores fazem uma discussão a respei- 
to das metodologias usadas para avaliar os riscos de cada substância no organismo. Eles apontam algumas problemáticas e limitações das metodologias de pesquisas cientificas no campo das substâncias químicas.

Lachenmeier e Rehm (2015) entendem que, de forma geral, os estudos são feitos em animais em ambientes muito diferentes das condições em que vivem os seres humanos. Quando levamos em conta a vida humana é preciso pensar sobre a multiplicidade de modos de existência, nesse sentido, o risco do uso de drogas é extremamente variável, sendo difícil ter resultados precisos em termos de efeitos gerais do uso de drogas para população geral. Os estudos acabam tendo resultados generalizantes que, na maioria das vezes, subestimam ou superestimam o efeito de alguma droga. Exemplo disso é a maconha, que durante muito tempo foi colocada no patamar das drogas nocivas, e atualmente tem sido apresentada como uma das substâncias que tem menor nível de toxidade, sendo inclusive utilizada de forma regulamentada para fins terapêuticos em determinadas doenças.

Grande parte dos danos do uso de drogas não estão relacionados ao consumo, mas fortemente influenciados pelas condições ambientais do uso, pelo uso concomitante com outras substâncias químicas, e esse risco adicional não está incluído na análise de drogas com base em toxicologia animal. Exemplo muito frequente disso, a partir de nossa experiência com usuários de drogas, se refere a diferença do uso da mesma substância em classes sociais divergentes. Por vezes, a falta de infraestrutura econômica acarretará em grandes danos a um usuário de drogas de classe popular, quando um usuário de classe média (consumidor da mesma droga) pouco se afetará. Ter uma má alimentação, precário acesso a higiene, má qualidade de sono (devido a uma infraestrutura precária ou o a um contexto social hostil), excessiva carga horária de trabalho e não ter acesso aos Direitos Sociais previstos na Constituição Federal (lazer, 
transporte, educação, saúde, etc.) (BRASIL, 1988) influenciará na precarização da vida do usuário, potencializando os efeitos danosos da substância.

Essa variabilidade de reações frente ao uso de drogas nos faz questionar seriamente o que, de fato, se define por drogas. Definimos por droga determinada substância devido a algum tipo de efeito que ela nos causa? Drogas seriam tudo aquilo que consumimos e que nos trazem malefícios? E porque, de forma geral, levando em conta as diversas classes sociais que fazem uso de drogas, apenas uma classe mais desfavorável acaba sendo punida e criminalizada?

Os conceitos relatados pelos profissionais na atividade para pensar sobre o que são drogas nos ajudam a ampliar a análise sobre essas questões. Para isso, através das 25 respostas, criamos 5 grandes temas que permearam o levantamentos e discussões daquele encontro, foram eles: 1) Drogas e Saúdes; 2) Drogas e Efeitos; 3) Drogas e Materialidades; 4) Drogas e Seres Humanos; 5) Drogas e Conceitos.

\section{Drogas e Saúdes}

Drogas como algo que faz mal ao organismo

Drogas como algo prejudicial à saúde

Drogas como algo que precisa de tratamento

Drogas como algo que leva a dependência e ao vício

Drogas como algo que toma o lugar na vida das pessoas aprisionando-as

Será que realmente as drogas fazem mal para o organismo? $\mathrm{O}$ que de fato faz mal ao organismo? Vamos pensar em um exemplo: Uma pessoa fuma um baseado, ou toma um copo de cerveja, já outra pessoa, toma de uma só vez 5 litros de água. Quem vai ter o 
organismo prejudicado? A droga é algo que nos leva necessariamente a dependência? Toda pessoa que bebe um copo de vinho é um dependente? Toda pessoa que cheira cocaína é uma dependente?

A dependência pode ser uma forma de se relacionar com as drogas, mas não é a única. Não é a substância que aprisiona, mas a forma como a pessoa se relaciona com a substância que a coloca, ou não, num aprisionamento. As drogas em si não necessariamente trazem malefícios ao organismo, já que o que causa mal estar ao organismo depende da forma como os sujeitos introduzem a droga no seu cotidiano. Se a droga for introduzida na vida como elemento principal da existência, provavelmente é uma existência-droga que será produzida na vida do sujeito. E isso não se refere apenas ao consumo de substâncias químicas, pois tudo aquilo que se torna única fonte de significação da existência para alguém (seja pela religião, sexo, consumo, política, esporte, etc.) pode reduzir o sujeito a uma unicidade existência-objeto.

O risco possível de existências pautadas em apenas um modo de ser é a limitação das possibilidades de vida que os sujeitos passam a impor no seu cotidiano. Circular sempre nos mesmo lugares, se relacionar sempre com as mesmas pessoas, viver preso em circuitos pré-estabelecidos em torno de objetos que consome. Um exemplo frequente disso, é em relação a aqueles usuários que anteriormente tinham o consumo de alguma substancia química como centralidade em suas vidas e, como estratégia de cura, são apresentados a religião e essa nova religião torna-se centralidade na vida do sujeito. O sujeito deixa de ser um fanático-dependente da droga para tornar-se um fanático-dependente da religião.

O uso por si só de substancias químicas não necessariamente tornam um sujeito dependente. E este argumento se torna evidente quando percebemos que grande parte dos profissionais que responderam à enquete já utilizaram algum tipo de substância: LSD, 
cocaína, maconha, álcool, cigarro, dentre outras. Podemos dizer que todos esses profissionais são dependentes porque em algum dia de suas vidas já fizeram ou fazem uso de alguma substância considerada droga? Por esses usos eles, necessariamente, teriam problemas de saúde e precisariam ser tratados como viciados?

Por que algumas pessoas ficam dependentes e outras não? Por que algumas pessoas ficam dependentes de uma relação afetiva, do trabalho, da comida, da ginástica, por exemplo, e outras não? Quando pensamos a dependência de forma ampla podemos ver que ela se trata de uma relação. Relação que um ser humano estabelece com as coisas ou com as pessoas. Nesse sentido, a droga em si não leva ninguém à dependência. Ninguém usa crack uma vez e já se torna dependente. Aliás, é justamente esta ideia - de que usar uma vez o crack já o torna dependente - muito difundida em campanhas midiáticas - que tem causado dificuldades no tratamento com pessoas usuárias dessa substância. Elas passam a acreditar que, por terem consumido apenas uma vez estariam "perdidas" (SIC) e por isso "não conseguem mais deixar o seu vício" (SIC). As campanhas, nessa perspectiva, fazem um desfavor social ao transmitir esse discurso que estereotipa os sujeitos e os impossibilita de pensar sobre as drogas como apenas um dos elementos possíveis em suas existências.

\section{Drogas e Efeitos}

Drogas como algo que altera o funcionamento psíquico ou físico Drogas como algo que nos aciona o prazer Drogas como algo que substitui uma frustração, insegurança Drogas como algo que modifica nossas emoções Drogas como substâncias que provocam sensações 
Sim, as drogas provocam sensações e modificam nossas emoções, assim como outros elementos que não são nomeados como drogas podem provocar. Porém, nem sempre o uso de uma substância altera emoções e comportamentos. Muitas vezes, acompanhamos pessoas que usaram uma substância e não sentiram absolutamente nada, nenhuma mudança, seja física, psíquica ou emocional. Nesse raciocínio, se formos remeter a expressão "estados alterados" sugerimos recolocar essa questão, apontando previamente: alterados a partir de quais parâmetros de normalidade?

Diversas pessoas que escutam música relatam sentir diferentes emoções ao ponto considerarem, significativamente, que seu comportamento fora alterado. E, por exemplo, estrategicamente teremos muitas academias de ginástica utilizando-se de músicas com ritmos fortes como forma de dar ânimo e estimular as pessoas a melhorar o desempenho nos exercícios (RODRIGUES; COELHO FILHO, 2012). Outro exemplo, são as religiões que se utilizam de ritmos musicais e até de alterações na voz (estimulando gritos e cantorias), para induzir as pessoas a um estado de transe. Podemos, então, dizer que músicas e ondas sonoras são drogas? Podemos falar que uma festa - momento em que as pessoas muitas vezes mudam o comportamento pelo uso da música - seria um ritual para uso dessa "droga" sonora? Podemos pensar que diversos rituais religiosos - em que nitidamente as pessoas estão alteradas são espaços de uso de drogas? E, revertendo a questão: existiriam usos de algo na vida que não influenciariam em nosso funcionamento psíquico e físico? Vamos proibir todos de comerem, terem relações sexuais ou fazerem compras apenas porque algumas pessoas fazem uso disso de forma compulsiva, negativa e dependente?

Outro ponto importante para pensarmos sobre o que são drogas e efeitos se refere a tendência que temos em desenvolver um olhar sobre o usuário muito focado para a questão do uso de drogas e perdemos de vista outras contingências de sua vida. Para muitos 
profissionais dos serviços o objetivo final de um atendimento seria levar o usuário à abstinência, mas, essa ação nega, por vezes, que esse uso existe para dar conta de outras demandas da vida daquele sujeito.

Vamos pensar dois exemplos. Um desses exemplos foi contado a partir da experiência de um Redutor de Danos que trabalhava com a população de rua. Nele, a equipe se deparou com o caso de uma adolescente de 13 anos que tinha um uso prolongado de crack. De uma forma geral, o que se pensaria é que era preciso fazer um tratamento no sentido de eliminar a dependência dessa adolescente. O foco neste caso seria a droga. Porém, essa equipe ao invés de pensar somente na questão do uso de crack, optou por ter um olhar mais ampliado sobre a vida dessa adolescente. Em uma das conversas, a adolescente então diz: "eu uso o crack, para poder suportar a dor de fazer sexo" (SIC).

No caso dela a prostituição servia como estratégia de sobrevivência, pois era de onde ela obtinha recursos para obter alimento. O crack, nesse exemplo, era uma ferramenta que ela usava para suportar suas condições de vida. Tirar essa ferramenta dela de forma autoritária e abrupta poderia ter consequências negativas sobre a forma como ela organizava sua vida. Por isso, não podemos atuar tendo focos e objetivos a priori da realidade dos sujeitos, anterior ao encontro e ao diálogo com cada pessoa, já que a droga possui efeitos e funções diferentes e, por isso, demandará tratamentos singulares. É no encontro e no diálogo que podemos construir um plano com a pessoa dentro de suas necessidades e possibilidades. Se acreditamos que apenas a abstinência é o caminho, vamos deixar de ver outras questões importantes da vida dessas pessoas, e por vezes vamos construir projetos terapêuticos que fracassarão ou podem ter consequências negativas importantes na vida do usuário.

Outro caso semelhante, foi de um rapaz que relatou ter feito uso de maconha em um momento de profunda tristeza, quando ele 
pensava em suicídio. A maconha, nessa situação, servia como um efeito anestésico da realidade, permitindo um prolongamento da vida do jovem, pela suspensão e afastamento das ideias de suicídio. Alguém que está de fora do contexto desses exemplos pode emitir muitos julgamentos morais pré-concebidos a partir de sua estrutura emocional própria, porém, no cuidado com usuários de drogas, é necessário legitimar que é o sujeito que tem conhecimento sobre sua própria vida: só quem está passando a situação para sentir e saber o que significa o uso de substâncias no seu cotidiano. Muitas vezes, ao contrário do que muitos discursos hegemônicos de criminalização das drogas tentam impor - que a droga enfraquece a pessoa -, é na droga que muitas pessoas encontram força para resistir e sobreviver. Por isso, enfatizamos a extrema importância de não termos uma única visão sobre o uso de substâncias, mas sim sempre pensando sobre a singularidade de cada uso da droga, buscando ter uma escuta ampliada do que significa esses usos e qual a funcionalidade dele na vida de cada pessoa.

\section{Drogas e Materialidades}

Drogas como substâncias químicas ou naturais

Drogas como algo concreto, visível

Drogas como um objeto que deve ser ingerido

Drogas como algo palpável, uma materialidade

Segundo a Organização Mundial de Saúde (OMS) 'droga' é um nome genérico dado a todo o tipo de substância, natural ou sintética, que ao ser introduzida no organismo provoca mudanças em suas funções (WORLD HEALTH ORGANIZATION, 1992). Se droga é considerada a partir de uma materialidade, somos convocados a deixar de lado muitos dos exemplos presentes no relato dos profis- 
sionais sobre aquilo que eles consideram como droga: trabalho, uso de tecnologias, religião, consumo, etc.

O relato deles nos provoca a pensar sobre as drogas por uma outra perspectiva: afinal, essas coisas não são substâncias, não possuem uma materialidade, isso significa que não poderiam ter um efeito inebriante e alucinógeno sobre a realidade? Por não serem um objeto palpável, significa que não são capazes de viciar e trazer impactos negativos na vida das pessoas?

Podemos definir as drogas como substâncias advindas da natureza ou como substâncias criadas em laboratório, mas, ampliando a análise sobre nossas vidas, torna-se possível pensar que essas substâncias também podem ser produzidas pelo nosso próprio organismo, a partir de vários setores da vida, por discursos, pensamentos, ideias, comportamentos ou papéis sociais que adotamos. A ideia de satisfação, como um fim almejado quando se usa uma droga, pode ser vinculada a várias outras esferas de nossas vidas: quando conquistamos um novo cargo de trabalho, quando atingimos um efeito muscular depois de meses em uma academia, quando seduzimos aquela pessoa desejada, quando obtemos uma determinada nota na escola, quando compramos um objeto que almejávamos... todos esses exemplos, e muitos outros, falam de um comportamento humano em busca de algo externo a nós para atingir a satisfação. Satisfação essa que traz prazer e também pode ter muitos efeitos negativos.

A busca de satisfação é algo quase que inerente ao humano. A droga pode ser uma das vias para atingir essa satisfação, mas ela não é a única. A prática de esportes radicais, por exemplo, atua na liberação de hormônios como forma de sentir prazer. E, por isso, muitas vezes dizemos: "O fulano é viciado em adrenalina!". Fazer corrida de carros em centros urbanos também pode ser um comportamento com fim satisfacional e perigoso para quem o faz e para o seu entorno. Neste sentido, pensar sobre o que são drogas, contra- 
pondo a um simplismo da materialidade, permite-nos refletir que é a relação que o ser humano estabelece com a sua satisfação que poderá, ou não, ser problemática para ele e seu entorno. Deveríamos proibir e criminalizar o uso de automóveis já que algumas pessoas os usam como dispositivo de satisfação ou dependência?

\section{Drogas e Seres Humanos}

Drogas como escape ou fuga

Drogas como potencializadoras ou aliviadoras de sensações

Drogas como mediadoras de encontros sociais

Drogas como algo inerente a cultura humana

A droga é uma substância inanimada, logo somos nós seres humanos vivos, desejosos e pensantes que significamos e atuamos em cima das substâncias. E é essa significação que vai moldar a forma como vamos nos relacionamos com as coisas. Muitas pessoas, talvez por tanto escutarem que droga vicia, acabam por perder a dimensão de seu potencial de relação com as coisas, significando demais objetos inanimados e esquecendo de seu protagonismo e responsabilidade na forma como se relacionam elas. Substâncias estão paradas, é o ser humano que se impulsiona sobre as mesmas. Droga é algo que nos relacionamos. A ação sobre algo está em nós (humanos) e não nas substâncias. Elas não nos possuem, nós as possuímos.

O debate com os profissionais na atividade para pensar o que são drogas nos fez colocar em análise a ideia de droga como algo contraposto ao ser humano. Droga é uma palavra relativamente atual, cunhada a pouco tempo dentro da história humana. Sua noção como algo pejorativo, que faz mal e precisa ser evitado, é um discurso fabricado mais intensamente no último século. $O$ uso de substâncias é algo que sempre esteve presente nas culturas huma- 
nas. Esses usos podiam se dar de forma individual (no caso de alivio de dores, ampliação do espirito, satisfação, etc.), e tinham funções sociais, tais como comunhão com o coletivo, ritos religiosos, festejos, etc. (GUARESCHI et al., 2015). Até hoje isso não é diferente, tanto é que o álcool muitas vezes é chamado de 'lubrificante social'. Dessa forma, não almejamos sermos hipócritas e querermos convencer você leitor que existe uma sociedade isenta do uso de drogas como muitas campanhas antidrogas discursam. As drogas não são ameaças aos humanos, são os humanos que se utilizam delas.

\section{Drogas e Conceitos}

Drogas um conceito múltiplo

Drogas como uma palavra diversa em sentidos

Drogas um conceito em constante construção

Drogas como um termo indefinível

Outro elemento interessante do levantamento que tinha como intenção estimular o pensar sobre o que são drogas foi perceber que, mesmo entre os profissionais das políticas públicas, não existe um único significado sobre drogas. E, por essa constatação, se não há uma única maneira de enxergar o fenômeno do uso de substâncias, também não existiria uma única maneira de lidar com este fenômeno. O conceito de drogas torna-se então um conceito múltiplo, por vezes indefinível ou embasado por valores morais, naturalizações, determinismos simplistas ou posições aleatórias.

Também não podemos esquecer - como foi dito anteriormente - que os usos de substâncias sempre estiverem presentes nas culturas humanas e, a forma como lidamos com esses usos, é algo que se transforma ao longo do tempo. Se hoje a cocaína é proibida, a pouco tempo ela era usada como medicamento (GURFINKEL, 
2008). Drogas torna-se conceitos em constantes transformações. A Marijuana, por exemplo, nome como é chamada a maconha no país do Paquistão, é encontrada em uma produção de alta escala (e alto índice de consumo) em diversos países, incluindo países asiáticos (BAESSO, 2013). Neles, é possível encontrarmos plantações da erva em locais comuns, como em meio a cidade. Em muitos dos países em que a maconha é regulamentada utiliza-se dela, também, por seu efeito medicinal.

Assim, a significação (da maconha como droga ilícita) faz parte de nossa construção cultural hegemônica brasileira e denuncia um determinado modo de constituir uma sociedade. Olhar para uma planta por um viés criminalizante, situá-la como elemento ritualístico ou medicinal são três exemplos diferentes que nos fazem visualizar os múltiplos entendimentos que podemos ter sobre uma mesma substancia. Deste modo, as ideias que temos sobre drogas enquanto conceitos dependerão das grades de inteligibilidade das diferentes constituições sociais, incluindo a forma como a população interpreta os elementos associados a substância (como algo sagrado, criminalizado ou curativo, por exemplo).

\section{Considerações nunca finais}

Ao propormos esse artigo, como uma estratégia de reflexão sobre a ideia das drogas, não tínhamos o objetivo de fazer apologia ao uso indiscriminado de substâncias químicas ou de modo algum levantarmos bandeiras e posicionamentos estanques frente aos debates sobre o tema. Ao trazermos para o foco de análise uma atividade de capacitação com profissionais das políticas públicas, iniciamos a escrita desse artigo fazendo uma provocação ao pensamento sobre algo que tantos humanos se orgulham: serem sujeitos racionais. A racionalidade é colocada como central na vida hu- 
mana, permitindo a criação de importantes meios de sobrevivência para a espécie, mas também pode-se tornar uma ferramenta de censura ao próprio pensar.

Desse modo, questionamos a forma como o debate sobre drogas ainda é envolto por muitas ações de censura e, assumindo a falência dessa estratégia nas políticas de cuidado que tem se mostrado eficazes, afirmamos a importância do pensar sobre as drogas como meio para o tratamento dos usuários que fazem uso problemático, com base na reflexão sobre o uso, responsabilização e autogestão de todos os envolvidos. Acreditamos, por nossas experiências no campo e pelos elementos aqui apresentados, que não nos cabe formular projetos terapêuticos pré-prontos: é necessário, frente as verdades apresentadas como absolutas no campo do uso de substâncias químicas, colocarmos mais interrogações do que respostas prontas.

Quando temos interrogações, pesquisamos mais, observamos e escutamos mais antes de agir. Ao escutarmos, construímos algo coletivo mais genuíno junto a aquele que nos fala. Frente aos usuários de drogas, e a complexidade que envolve sua vida, não devemos basear nossa prática em materiais teóricos que apenas nos conduzam a agir de forma vertical sobre as pessoas: precisamos ser e produzir sujeitos autônomos e não apoiarmos a produção de meros usuários assujeitados por discursos externos a si.

As discussões levantadas aqui apontaram para uma complexidade no campo do uso de drogas que não deve ser negada pelo pensar, mas usada como ferramenta na potencialização de cuidados singulares. O fenômeno do uso de substâncias é algo extremamente complexo. É preciso deslocarmos o foco da substância para conseguirmos olhar para tantos outros fatores além da droga que envolvem o fenômeno do consumo na vida dos sujeitos. Existem muitas 
variáveis na questão dos usos, tantas variáveis, que o que nos sobra é analisar cada caso na sua existência única e localidade situada. Compreendemos, enquanto profissionais que atuam na área, que seria confortável vivermos com técnicas estabelecidas a priori que nos mostrassem como deveríamos proceder diante de cada situação. Confortável, realmente, porém ilusório: ilusão de nossa suposta primazia da racionalidade que, pelo próprio uso do pensar, tenta nos ludibriar cegando-nos frente aos escapes de nossa razão.

Nós humanos nos orgulhamos de sermos seres racionais? Frente às drogas, sugerimos que esse orgulho deva ser mantido: Drogas, vamos pensar! Mas, nos atrevemos a dizer que com essa própria lógica, da razão como primazia humana, devemos ter uma certa desconfiança. Nossos sentimentos e comportamentos, por vezes contraditórios e complexos, provam que não somos máquinas previsíveis. Nossa racionalidade nos engana e nos surpreende e isso não deve ser desconsiderado quando estamos em frente de humanos, usuários de alguma substância química ou não, e somos convocados a construir políticas de cuidado junto a eles. Drogas, vamos pensar, para poder cuidar!

\section{Referências}

BAESSO, D. C. Cannabis: geografia econômica e política. 2013. 118 f.. Monografia (Graduação) - Instituto de Ciências Humanas, Universidade Federal de Juiz de Fora, 2013.

BRASIL. Portaria no 1.028, de 1ำ de julho de 2005. Determina que as ações que visam à redução de danos sociais e à saúde, decorrentes do uso de produtos, substâncias ou drogas que causem dependência, sejam reguladas por esta Portaria. Brasília: DF. 2005. 
BRASIL. Constitução (1988). Constituição [da] República Federativa do Brasil. DF: Brasília, 1988. Disponível em:

http://www.planalto.gov.br/ccivil_03/constituicao/ constituicao.html Acesso em 09 de outubro de 2016.

CECCIM, R. B. Educação Permanente em Saúde: desafio ambicioso e necessário. Interface, Botucatu, v. 9, n. 16, p. 161-168, fev. 2005 Disponível em:

$<$ http://www.scielo.br/scielo.php?script=sci artext\&pid= S1414$\underline{32832005000100013 \& \operatorname{lng}=e n \& n r m=i s o>}$ Acesso em: 09 out. 2016.

GÓIS, M. M. A.; AMARAL, J. H. O uso de drogas lícitas e ilícitas e suas consequências sociais e econômicas. Universidade Federal do Pará, 2016. Disponível em:

http://www.progep.ufpa.br/progep/docsDSQV/ALCOOL E DROG AS.pdf Acesso em: 09 out. 2016.

GOMIDE, H. P. et al. Estereótipos dos profissionais de saúde em relação a alcoolistas em Juiz de Fora-MG, Brasil. Psicologia: teoria e prática, São Paulo, v.12, n.1, p.171-180, 2010. Disponível em: http://pepsic.bvsalud.org/scielo.php?script=sci arttext\&pid=S15163687201000010 0014\&lng=pt\&nrm=iso Acesso em: 09 out. 2016.

GRUPO RBS. Guerra ao crack: um talk show para mobilizar o Estado. Zero Hora, Porto Alegre, 30 jun. 2009. p. 33. Disponível em: http://www.clicrbs.com.br/especial/sc/c racknempensar/home, 0,3710,Home.html Acesso em: 09 out. 2016.

GUARESCHI, N. M. F.; LARA, L.; ECKER, D. D. A internação compulsória como estratégia de governamentalização de adolescentes usuários de drogas. Estudos de Psicologia, Natal, v. 21, n.1, p.2535, mar. 2016. Disponível em: http://www.scielo.br/scielo.php?script $=$ sciarttext\&pid=S1413-294X2016000100025\&lng=em \&nrm=iso Acesso em: 09 out. 2016.

GUARESCHI, N. M. F et al. Archivos rio-grandenses de medicina de 1920 a 1943: uso do álcool e a construção do comportamento de risco. Mnemosine, v.11, n.2, 2015. Disponível em: 
http://mnemosine.com.br/ojs/index.php/mnemosine/article/view/443 1365 Acesso em: 09 out. 2016.

GURFINKEL, D. O episódio de Freud com a cocaína: o médico e o monstro. Revista Latinoamericana Psicopatologia Fundamental, São Paulo, v. 11, n. 3, p. 420-436, set. 2008. Disponível em: http://www.scielo.br/pdf/rlpf/v11 n3/06.pdf Acesso em: 09 out. 2016.

HÜNING, S. M; GUARESCHI, N. M. F. Efeito Foucault: desacomodar a psicologia. In: GUARESCHI, N. M. F.; HÜNING, S. (Orgs.) Michel Foucault e a Psicologia. Porto Alegre: Edipucrs, 2009. p. 159-182

LACHENMEIER, D. W; REHM, J. Comparative risk assessment of alcohol, tobacco, cannabis and other illicit drugs using the margin of exposure approach. Scientific Reports, n. 5, jan. 2015. Article number: 8126 doi: 10.1038/srep08126 Disponível em: < http://www.nature.com/srep/2015/150130/srep 08126/abs/srep08126.html\#supplementary-informationER $>$ Acesso em: 09 out. 2016.

PENNA, B. A lucta contra o alcoolismo. Archivos rio-grandenses de medicina. Porto Alegre. v. 8, n.12, dez. 1929.

RODRIGUES, N. S; COELHO FILHO, C. A. de A. Influência da audição musical na prática de exercícios físicos por pessoas adultas.

Revista Brasileira de Educação Física e Esporte, São Paulo, v. 26, n. 1, p. 87-95, mar. 2012. Disponível em: < http://www.scielo.br/scielo.php?script=sciarttext\&pid=S 180755092012000100009\&lng=en\&nrm=iso $>$ Acesso em: 09 out. 2016.

WORLD HEALTH ORGANIZATION. The ICD-10 classification of mental and behavioural disorders: clinical descriptions and diagnostic guidelines. Geneva: WHO, 1992. 